\title{
Glycine Is Used as a Transmitter by Decrementing Expiratory Neurons of the Ventrolateral Medulla in the Rat
}

\author{
Kazuhisa Ezure, ${ }^{1}$ Ikuko Tanaka, ${ }^{1}$ and Masahiro Kondo ${ }^{2,3}$ \\ Departments of ${ }^{1}$ Neurobiology and ${ }^{2}$ Molecular Physiology, Tokyo Metropolitan Institute for Neuroscience, Tokyo 183-8526, Japan, and ${ }^{3}$ Department of \\ Cancer Biology, Dana-Farber Cancer Institute, Boston, Massachusetts 02115-02446
}

The medullary respiratory network involves various types of respiratory neurons. The present study focused on possible inhibitory neurons called decrementing expiratory (E-DEC) neurons and aimed to determine whether their transmitter is glycine or GABA. In Nembutal-anesthetized, neuromuscularly blocked, and artificially ventilated rats we labeled E-DEC neurons with Neurobiotin and processed the tissues for detection of mRNA encoding either glycine transporter 2 (GLYT2) as a marker for glycinergic neurons or glutamic acid decarboxylase isoform 67 (GAD67) as a marker for GABAergic neurons, using in situ hybridization. Of 38 E-DEC neurons that were labeled, cranial motoneurons $(n=14)$, which were labeled as control, were negative for either GLYT2 mRNA $(n=10)$ or GAD67 mRNA $(n=4)$. The other E-DEC neurons $(n=24)$ were non-motoneurons. Sixteen of them were examined for GLYT2 mRNA, and the majority (11 of 16) was GLYT2 mRNA-positive. The remaining E-DEC neurons $(n=8)$ were examined for GAD67 mRNA, and all of them were GAD67 mRNA-negative. The GLYT2 mRNA-positive E-DEC neurons were located in the ventrolateral medulla spanning the Bötzinger complex (BOT), the rostral ventral respiratory group (VRG), and the caudal VRG. We conclude that not only E-DEC neurons of the BOT but also many E-DEC neurons of the VRG are inhibitory and use glycine as a transmitter. Although the present negative data cannot rule out completely the release of GABA or co-release of glycine and GABA from E-DEC neurons, several lines of evidence suggest that the glycinergic process is primarily responsible for the phasic inhibition of the respiratory network during the expiratory phase.

Key words: expiratory neuron; transmitter; glycine; in situ hybridization; GLYT2; GAD67

\section{Introduction}

Glycine and GABA, the major inhibitory neurotransmitters working in the medulla and the spinal cord, are involved in the brainstem network of respiratory neurons (Hayashi and Lipski, 1992; Paton and Richter, 1995; Pierrefiche et al., 1998; Haji et al., 2000). In particular, there is increasing evidence that glycine is an essential inhibitory transmitter for respiratory rhythmogenesis (Schmid et al., 1996; Iizuka, 1999; Schreihofer et al., 1999; Büsselberg et al., 2001; Dutschmann and Paton, 2002a,b). A substantial advance in understanding the medullary respiratory network recently has been achieved by Schreihofer et al. (1999), who have shown that glycine is the transmitter used by the augmenting expiratory (E-AUG) neuron of the Bötzinger complex (BOT), which are key neurons exerting extensive inhibitions on medullary respiratory neurons (Merrill et al., 1983; Ezure, 1990; Jiang and Lipski, 1990). The BOT includes another type of inhibitory neuron called the decrementing expiratory (E-DEC) neuron (Bianchi and Barillot, 1982; Lindsey et al., 1987; Ezure and Manabe, 1988; Bryant et al., 1993; Hayashi et al., 1996; Saito et al., 2002; Shen et al., 2003). The E-DEC neurons or possible correlates, postinspiratory neurons, are hypothesized to play an important

\footnotetext{
Received July 4, 2003; revised Aug. 12, 2003; accepted Aug. 12, 2003.

This work was supported in part by a Grant-in-Aid for Scientific Research for K.E. from the Japanese Ministry of Education, Culture, Sports, Science, and Technology.

Correspondence should be addressed to Kazuhisa Ezure, Department of Neurobiology, Tokyo Metropolitan Institute for Neuroscience, 2-6 Musashidai, Fuchu, Tokyo 183-8526, Japan. E-mail: ezurek@tmin.ac.jp.

Copyright $\odot 2003$ Society for Neuroscience $\quad$ 0270-6474/03/238941-08\$15.00/0
}

role in the inspiration-expiration phase transition (Richter et al., 1986; Duffin et al., 1995; Hayashi et al., 1996; Schmid et al., 1996; Rybak et al., 1997). It is our concern whether the E-DEC neurons of the BOT are glycinergic or GABAergic.

In addition to the BOT, E-DEC neurons or postinspiratory neurons are distributed throughout the ventral respiratory group (VRG) (Feldman and Cohen, 1978; Schwarzacher et al., 1991; Shiba et al., 1997; Saito et al., 2002). Many of them are cranial motoneurons (Zheng et al., 1991; Saito et al., 2002), but some are interneurons with intramedullary projections to respirationrelated areas (Anders et al., 1991; Zheng et al., 1991; Schwarzacher et al., 1992; Shiba et al., 1997; Saito et al., 2002). However, their role is unexplored as yet. We aimed to examine the possibility that the E-DEC neurons of the VRG are also inhibitory and use glycine or GABA as their transmitter.

To determine the inhibitory transmitter used by physiologically identified E-AUG neurons, Schreihofer et al. (1999) successfully used single neuron labeling combined with in situ hybridization for mRNA encoding glycine transporter 2 (GLYT2) (Liu et al., 1993; Luque et al., 1995; Chan and Sawchenko, 1998) or glutamic acid decarboxylase isoform 67 (GAD67) (Erlander et al., 1991; Chan and Sawchenko, 1998; Stornetta and Guyenet, 1999). To date, this in situ hybridization technique may be the most powerful method to identify glycinergic or GABAergic neurons, because it labels only cell bodies of the neurons that almost certainly use glycine or GABA as their neurotransmitter; the advantage of this method over the conventional immunohistochemical 
methods has been described fully previously (Esclapez et al., 1994; Chan and Sawchenko, 1998; Schreihofer et al., 1999; Stornetta and Guyenet, 1999). We then also used single neuron labeling combined with in situ hybridization for GLYT2 mRNA or GAD67 mRNA.

\section{Materials and Methods}

We performed all experimental procedures in accordance with the Guiding Principles for the Care and Use of Animals in the Field of Physiological Science (Physiological Society of Japan, 2001). The experiments were reviewed and approved by the Animal Care and Use Committee of the Tokyo Metropolitan Institute for Neuroscience.

Surgical procedures. Data were obtained from adult Wistar rats $(320-$ $430 \mathrm{gm} ; n=11$ ) anesthetized with pentobarbital sodium (Nembutal, 70 $\mathrm{mg} / \mathrm{kg}$, i.p.; Abott Laboratories, North Chicago, IL); supplementary doses of the anesthetics $(\sim 5 \mathrm{mg} / \mathrm{kg}$ per hr, i.v.) were given throughout the experiment and the survival period. The trachea was intubated, and cannulas were placed in the femoral artery to monitor blood pressure and in the femoral vein for drug administration. The rats were placed in a stereotaxic frame, and occipital craniotomy and partial cerebellectomy were performed to expose the dorsal surface of the medulla. The isolated C4/5 phrenic nerve root was cut distally, and the central stump was mounted on a bipolar electrode for recording. The vagus nerves including the superior laryngeal nerves were exposed on both sides and placed on bipolar-stimulating electrodes; on one side the pharyngeal branch also was included for stimulation. The rats were injected with the neuromuscular blocker pancronium bromide $(0.15 \mathrm{mg} / \mathrm{kg}$ per hr; Mioblock, Sankyo, Tokyo, Japan) and ventilated artificially with a positive end-tidal load of $1-2 \mathrm{~cm}$ of $\mathrm{H}_{2} \mathrm{O}$ after a bilateral pneumothorax. Tracheal pressure, end-tidal $\mathrm{CO}_{2}$ (kept at $3-5 \%$ ), and rectal temperature (kept at $36-37^{\circ} \mathrm{C}$ ) were monitored.

Identification of E-DEC neurons and tracer injection. Glass micropipettes for intracellular recording and tracer injection were filled with Neurobiotin (4\%; Vector Laboratories,, Burlingame, CA) in $0.5 \mathrm{M} \mathrm{KCl}-$ Tris buffer, pH 7.6. Recording and labeling of E-DEC neurons were performed in the ventrolateral medulla. Each E-DEC neuron was identified by its decrementing firing pattern during the expiratory phase. When the intracellular electrode touched each E-DEC neuron, we penetrated the neuron by passing brief positive current pulses through the electrode tip or by gently tapping a manipulator head. We did not intend to obtain well developed membrane potentials by fully penetrating the neurons, because in many cases good intracellular recordings resulted in simply killing the neurons. Some of our recordings were often juxtamembranous rather than intracellular recordings (Pinault, 1996; Schreihofer et al., 1999; Otake et al., 2001; Pilowsky and Makeham, 2001). Neurobiotin was injected by positive current pulses (50 $\mu \mathrm{sec} \mathrm{du-}$ ration; 4 or 5 pulses/530 msec; $3 \mathrm{nA}$ maximum intensity), and the injections normally were terminated at $2-3 \mathrm{~min}$.

We labeled both motoneurons and interneurons after discriminating between motoneurons and interneurons by electrically stimulating the vagus nerve. That is, we considered the neurons without antidromic activation as interneurons in the first place, because motoneurons with E-DEC activity are involved exclusively in the vagal nerve, but not in the glossopharyngeal nerve (Grélot et al., 1989). On the side in which we did not stimulate the pharyngeal branch of the vagus nerve, we sampled no E-DEC neurons in the rostral area (at the level $0.5 \mathrm{~mm}$ or more rostral to the obex) (Bieger and Hopkins, 1987), because interneurons and motoneurons were not distinguishable. However, in four experiments we sampled E-DEC neurons from such areas after examining antidromic activation of E-DEC neurons, using two tungsten electrodes (for monopolar stimulation) fixed in the caudal VRG within the area $1-1.5 \mathrm{~mm}$ caudal to the obex and 1.3-2.0 mm lateral to the midline. At the stage of data analysis, by observing the axonal trajectories and/or choline acetyltransferase (ChAT; see below) immunoreactivity of the labeled neurons, we further confirmed whether they were motoneurons or interneurons.

Histological procedures and morphological analysis. At least $30 \mathrm{~min}$ after the last tracer injection, under deep anesthesia with pentobarbital sodium, the rats were perfused transcardially with $200 \mathrm{ml}$ of physiological saline, followed by $350 \mathrm{ml}$ of $4 \%$ paraformaldehyde in $0.1 \mathrm{M}$ phosphate buffer (PB; $\mathrm{pH} 7.4$ ), which included $0.2 \%$ picric acid. The brain tissue was postfixed in the same solution overnight at $4^{\circ} \mathrm{C}$ and cryoprotected by immersion in $30 \%$ sucrose in $0.1 \mathrm{M} \mathrm{PB}$ until equilibrium. The brainstem was cut transversely at $50 \mu \mathrm{m}$ on a freezing microtome. The sections were collected in $0.1 \mathrm{M}$ PBS, treated sequentially (with intervening rinses in PBS) in $0.4 \%$ Triton X-100 in PBS for $20 \mathrm{~min}$, in $0.2 \mathrm{~N} \mathrm{HCl}$ in diethyl pyrocarbonate (DEPC)-treated water for $10 \mathrm{~min}$, in proteinase $\mathrm{K}(1.5$ $\mu \mathrm{g} / \mathrm{ml}$ ) in $0.1 \mathrm{M} \mathrm{PB}$ with $50 \mathrm{~mm}$ EDTA for $10 \mathrm{~min}$, in $4 \%$ paraformaldehyde in PBS for $20 \mathrm{~min}$, and kept in prehybridization solution (see below).

Preparation of RNA probes for GLYT2 $m R N A$ and GAD67 $m R N A$. Because the preparation of mRNA probes has been described fully previously (Tanaka et al., 2003), we describe it here only briefly.

The RNA probes for GLYT2 mRNA were generated from a cDNA encoding GLYT2 (3.5 kb; Liu et al., 1993). From a partial cDNA template (3.1 kb; a generous gift from Dr. N. Nelson, Tel Aviv University, Israel) $1.7 \mathrm{~kb}$ (702-2492) was isolated and further subcloned. The RNA probes for GAD67 mRNA were generated from a full-length cDNA encoding rat GAD67 (2.7 kilobases; Erlander et al., 1991). GAD67 DNA template inserted into the EcoRI site of pBluescript plasmid (a generous gift from Dr. A. J. Tobin, University of California, Los Angeles, CA) was used to transcribe riboprobes. Further procedures to obtain the riboprobes for GLYT2 mRNA and those for GAD67 mRNA were the same. The riboprobes (both sense and antisense) were obtained by linearizing the recombinant plasmids and transcribing them with RNA polymerases in the presence of digoxigenin (DIG)-labeled 11-UTP (Roche, Mannheim, Germany). The riboprobes were fragmented by limiting alkaline hydrolysis (Cox et al., 1984) to obtain probes of $\sim 250$ nucleotides in peak length.

In situ hybridization histochemistry. The basic procedures followed the protocols used in preceding studies (Ichikawa et al., 1997; Kondo et al., 1997); the details have been described by Tanaka et al. (2003). The prehybridization mixture was an aqueous solution of $0.3 \mathrm{M} \mathrm{NaCl}, 20 \mathrm{~mm}$ Tris- $\mathrm{HCl}, \mathrm{pH} 8.0$, and 50\% formamide in DEPC-treated water. The hybridization mixture included, in addition to these, Escherichia coli tRNA $(0.5 \mathrm{mg} / \mathrm{ml}), 2.5 \mathrm{~mm}$ EDTA, Denhardt's $(0.02 \%$ bovine serum albumin, $0.02 \%$ Ficoll (Sigma, St. Louis, MO), $0.02 \%$ polyvinylpyrrolidone), $0.1 \%$ Tween 20 (Sigma), and riboprobes $(0.2 \mu \mathrm{g} / \mathrm{ml}$ ). The brain sections (freefloating) were incubated in prehybridization mixture for $1 \mathrm{hr}$ at $50^{\circ} \mathrm{C}$ and then transferred to the hybridization solution for $16 \mathrm{hr}$ at $50^{\circ} \mathrm{C}$. The sections were washed in $2 \times$ standard saline citrate (SSC) with $50 \%$ formamide at $50^{\circ} \mathrm{C}$, followed by a rinse in RNase buffer (Tris- $\mathrm{HCl}$ including $500 \mathrm{~mm} \mathrm{NaCl}, \mathrm{pH} 8.0$ ), incubation in RNase A (Roche) solution (20 $\mu \mathrm{g} / \mathrm{ml}$ in RNase buffer) for $30 \mathrm{~min}$ at $37^{\circ} \mathrm{C}$, and a rinse in RNase buffer. The sections were washed in $2 \times$ SSC with $50 \%$ formamide at $50^{\circ} \mathrm{C}$ for 1 $\mathrm{hr}$ and twice in $1 \times \mathrm{SSC}$ with $50 \%$ formamide at $50^{\circ} \mathrm{C}$ for $1 \mathrm{hr}$.

The DIG-labeled riboprobe was revealed by incubating the sections with a sheep polyclonal anti-DIG antibody conjugated to alkaline phosphatase (Roche). The blue/brown reaction product was produced by incubation of the sections in a solution of $0.1 \mathrm{M} \mathrm{NaCl}, 50 \mathrm{mM} \mathrm{MgCl}_{2}$, and $0.1 \mathrm{~m}$ Tris- $\mathrm{HCl}, \mathrm{pH}$ 9.5, with nitroblue tetrazolium and 5-bromo-4chloro-3-indolyl-phophate, 4-toluidine salt (NBT/BCIP kit, $20 \mu \mathrm{l} / \mathrm{ml}$; Roche) in the dark at room temperature for $1-2 \mathrm{hr}$. The length of this reaction time was determined by using a dissecting microscope to observe periodically the reaction product develop. By using a separate set of sections, we treated the corresponding sense riboprobes with the same protocols.

Immunohistochemistry for choline acetyltransferase. In two rats, after the alkaline phosphatase reaction, the sections were processed further for detection of ChAT. Free-floating sections were incubated with rabbit antibody against rat ChAT (1:1000; Ichikawa et al., 1991) (a generous gift from Ms. K. Ajiki and the late Dr. T. Ichikawa, Tokyo Metropolitan Institute for Neuroscience, Japan) in PBS for $16 \mathrm{hr}$ at $4^{\circ} \mathrm{C}$ and then with an amino acid polymer (Histofine, simple-stain-rat, MAX-PO; Nichirei, Tokyo, Japan) that is conjugated with both anti-rabbit IgG and HRP for $30 \mathrm{~min}$ at room temperature. Then the HRP was reacted with tyramidefluorescein isothiocyanate (FITC; PerkinElmer, Boston, MA) for fluorescent microscopy. 
Neurobiotin-labeled neurons. Neurobiotin-labeled neurons were visualized by incubating sections with streptavidin indocarbocyanine (Cy3; 1:200; Jackson ImmunoResearch, West Grove, PA) for $1 \mathrm{hr}$ at room temperature.

Data analysis. The sections were mounted on a MAS-coated glass slide (Matsunami Glass, Osaka, Japan) and covered with Vectashield (Vector Laboratories). A fluorescence microscope together with an image acquisition system Argus-20 (Hamamatsu Photonics, Hamamatsu, Japan; resolution, $512 \times 483$ points, eight-bit grayscale) was used to find Neurobiotin-labeled neurons and to examine ChAT immunoreactivity and alkaline phosphatase reaction product (bright-field) for GLYT2 mRNA or GAD67 mRNA. When photomicrographs in the bright-field only were required, digital images with higher resolution $(2048 \times 1536$ points, eight-bit grayscale) were used.

Several anatomical landmarks and nomenclature were used according to Paxinos and Watson (1998). Although identifying detailed anatomical structures in the present noncounterstained sections was difficult, we were able to identify many structures, such as the solitary tract, the inferior olivary nucleus, the spinal trigeminal tract, or the hypoglossal nucleus under the bright-field microscope because of slight differences in reflection and/or refraction properties of the tissue. In the present analysis we define the caudal end of the area postrema as "the obex" and use it as the reference, which approximately corresponds to Bregma $-14 \mathrm{~mm}$ in the atlas of Paxinos and Watson (1998).

\section{Results}

We examined serial frontal sections of the medulla from the level of the facial nucleus through the level of the pyramidal decussation for identification of Neurobiotin-labeled neurons and for detection of GLYT2 mRNA in six rats and GAD67 mRNA in five rats. In addition, we examined ChAT immunoreactivity in two of the six rats for GLYT2 mRNA detection. We analyzed 38 E-DEC neurons, including cranial motoneurons and interneurons (nonmotoneurons), which were visualized successfully and identified unequivocally. These neurons were located in the ventrolateral medulla in association with the nucleus ambiguus and the nucleus retroambiguus.

\section{Control study}

First, we examined, in every rat, a few control sections including the trapezoid nucleus for detection of GLYT2 mRNA and the cerebellar cortex for detection of GAD67 mRNA. The respective antisense probe, but not the sense probe, labeled glycinergic neurons in the trapezoid nucleus and GABAergic neurons in the cerebellar cortex (Fig. 1). In both GLYT2 mRNA-positive (GLYT2-positive) neurons and GAD67 mRNA-positive (GAD67-positive) neurons, alkaline phosphatase reaction product was revealed in the cytoplasm surrounding the nucleus, but not within the nucleus. Second, we labeled three E-AUG neurons in the BOT; they were GLYT2-positive (Schreihofer et al., 1999) (Fig. 2). Third, 14 of the 38 E-DEC neurons were cranial motoneurons that we labeled as control data. Thirteen of these were labeled after confirming antidromic activation by electrical stimulation of the vagus nerve (Fig. 3), and one later was revealed to be a motoneuron by a Neurobiotin-labeled axon. We could observe characteristic axonal trajectories, which coursed dorsomedially first, turned ventrolaterally, and went out of the brainstem (data not shown) (Saito et al., 2002) in 11 of these 14 motoneurons. When ChAT immunoreactivity was examined in one motoneuron, it was ChAT-positive (Fig. 3). These motoneurons were located in the nucleus ambiguus or the nucleus retroambiguus (Fig. 4), and all were negative either for GLYT2 mRNA $(n=10)$ or for GAD67 mRNA $(n=4$; Fig. 3$)$.
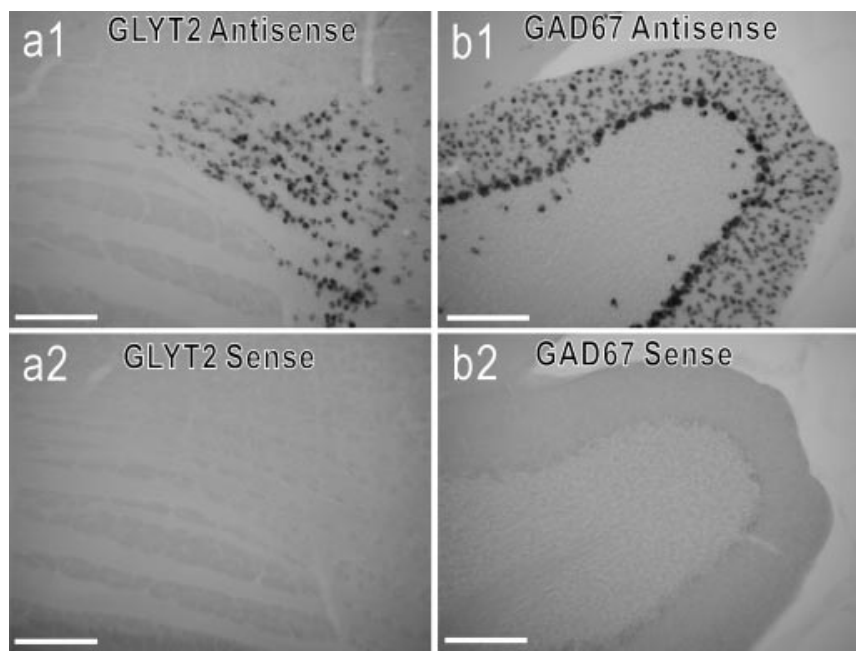

Figure 1. Control labeling for GLYT2 mRNA and GAD67 mRNA. Shown are photomicrographs of labeling in $50 \mu \mathrm{m}$ sections at the level of the trapezoid nucleus for GLYT2 mRNA $(a 1, a 2)$ and in sections of the cerebellar cortex for $\operatorname{GAD67} \mathrm{mRNA}(b 1, b 2)$. Also shown are antisense riboprobe $(a 1, b 1)$ and sense riboprobe $(a 2, b 2)$. Scale bars, $200 \mu \mathrm{m}$.
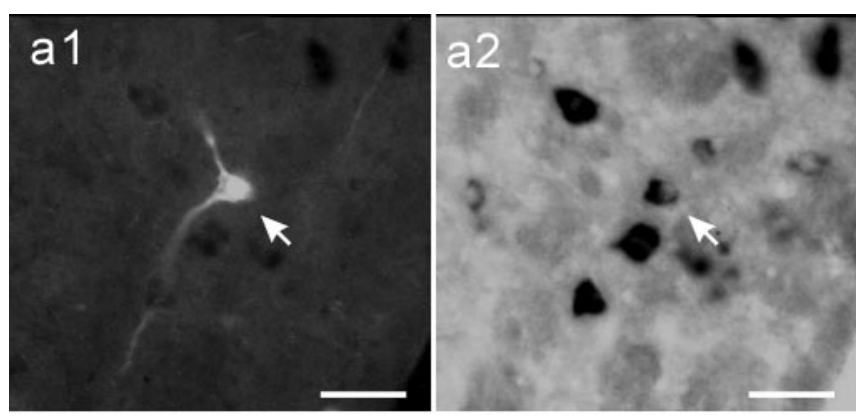

\section{a3}

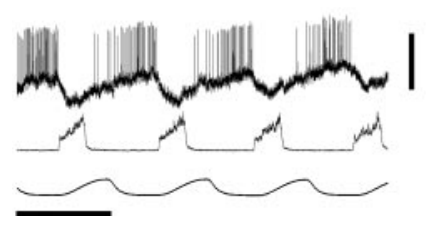

a4

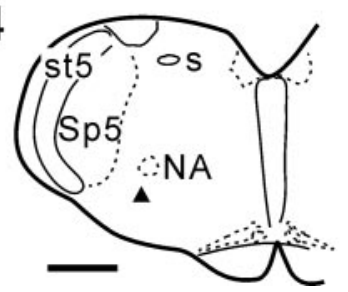

Figure 2. GLYT2 mRNA in E-AUG neuron of the BOT. a1, Photomicrograph of a Neurobiotinlabeled E-AUG neuron (arrow, Cy3 fluorescence). a2, Photomicrograph of the same area of $a 1$ shown in bright-field for GLYT2 mRNA. Intracellular activity ( $a 3$, top trace) exhibited augmenting expiratory activity. a3, Middle trace, Integrated phrenic nerve activity. a3, Bottom trace, Tracheal pressure. 04 , Location of this neuron (filled triangle) at the level just caudal to the facial nucleus. NA, Nucleus ambiguus; s, solitary tract; Sp5, spinal trigeminal nucleus; st5, spinal trigeminal tract. Scale bars: a1, a2, $50 \mu \mathrm{m} ; a 4,1 \mathrm{~mm}$. Calibration: $a 3,1 \mathrm{sec}, 20 \mathrm{mV}$.

\section{Identification of E-DEC neurons and detection of GLYT2 mRNA}

Twenty-four of the 38 E-DEC neurons were interneurons. First, none of them $(n=24)$ was activated antidromically from the vagus nerve. Second, these neurons possessed at least one of three features: (1) in experiments in which ChAT immunoreactivity was checked, the E-DEC neurons that were examined $(n=11)$ were ChAT-negative; (2) when Neurobiotin-labeling revealed enough length of axonal trajectories, these neurons $(n=15)$ showed intramedullary axon collaterals or projections; and (3) some of them recorded in the BOT area $(n=7)$ were activated antidromically by electrical stimulation of the caudal VRG area (Fig. 5). When the mean diameters (algebraic mean of the major 

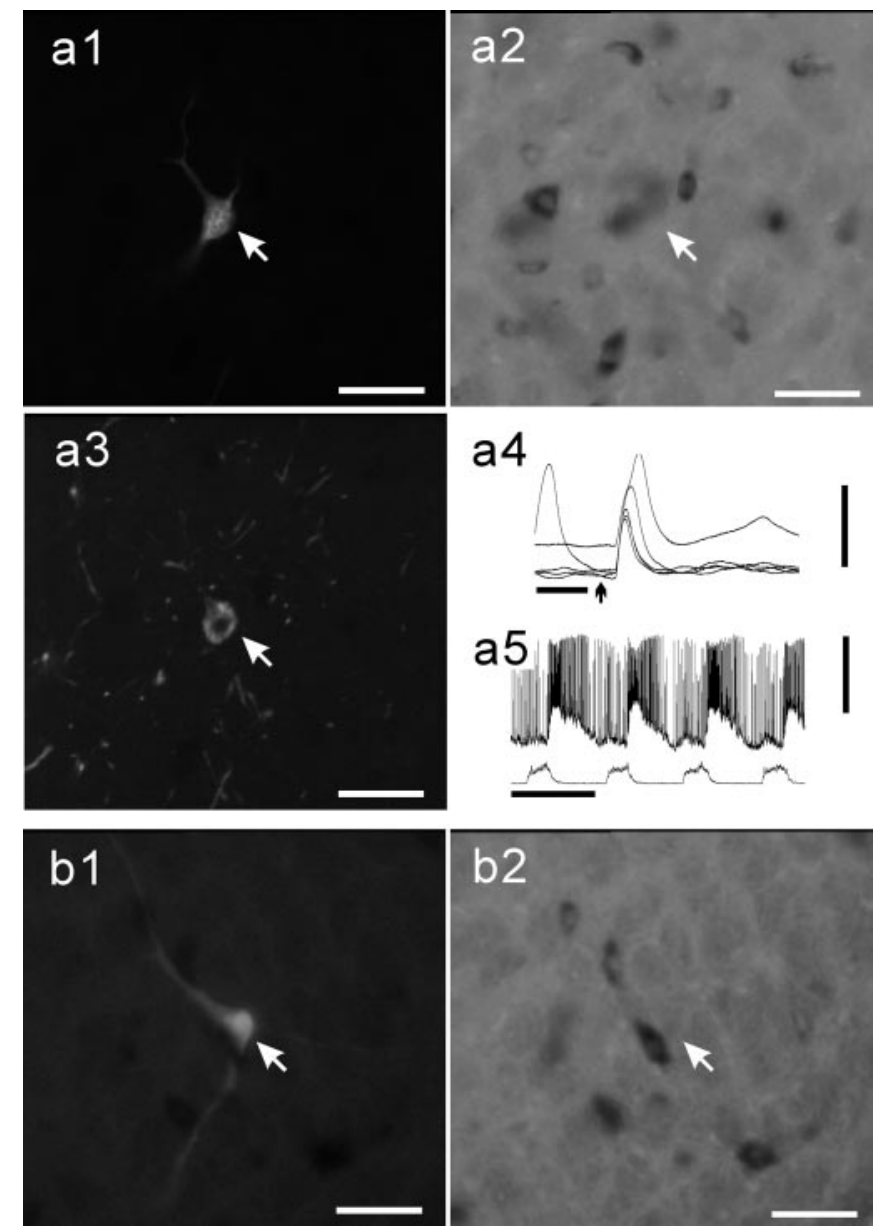

Figure 3. Negative labeling of motoneurons for GLYT2 mRNA and GAD67 mRNA. A vagal motoneuron labeled with Neurobiotin ( $a 1$, arrow) exhibits ChAT immunoreactivity ( $a 3$, arrow) but is GLYT2-negative ( $a 2) . a 1, a 2$, and $a 3$ are the same area. This neuron was activated antidromically by electrical stimulation (arrow) of the vagus nerve (a4). Intracellular activity ( $a 5$, top trace) exhibited decrementing expiratory activity. a5, Bottom trace, Integrated phrenic nerve activity. Another vagal motoneuron labeled with Neurobiotin (b1, arrow) is GAD67negative (b2). $b 1$ and $b 2$ are the same area. Scale bars: $50 \mu \mathrm{m}$ for photomicrographs. Calibration: $a 4,5 \mathrm{msec}, 20 \mathrm{mV} ; a 5,1 \mathrm{sec}, 20 \mathrm{mV}$.

and minor axes estimated from fluorescent labeling) were used as the value representative of somal size, they ranged from 12.0 to $28.8 \mu \mathrm{m}$, and the mean $( \pm \mathrm{SD})$ was $18.6 \pm 6.08 \mu \mathrm{m}(n=24)$.

Eleven of the 16 E-DEC neurons examined for GLYT2 mRNA were GLYT2-positive (Figs. 5, 6), and the other five were negative (Fig. 7). GLYT2-positive neurons were located in the BOT (Figs. 4, 5), rostral VRG (Figs. 4, 6), and caudal VRG (Figs. 4, 6). The remaining eight E-DEC neurons were examined for GAD67 mRNA and were GAD67-nagative (Fig. 7). The present fluorescent labeling was not suitable for detailed analysis of axonal projections or dendritic arborizations, and we noted no special differences in morphology between GLYT2-positive and GLYT2negative neurons. The firing properties and membrane potential trajectories of the E-DEC neurons labeled varied to some extent. The depolarization of some interneurons started at late inspiratory phase (early-onset type; Fig. 6), and their initial spikes tended to overlap with the inspiratory phase. In contrast, the membrane potentials of the majority of motoneurons and some interneurons tended to stay hyperpolarized until the end of the inspiratory phase and depolarized suddenly at the inspirationexpiration transition (Figs. 3, 7). Although the present quality of
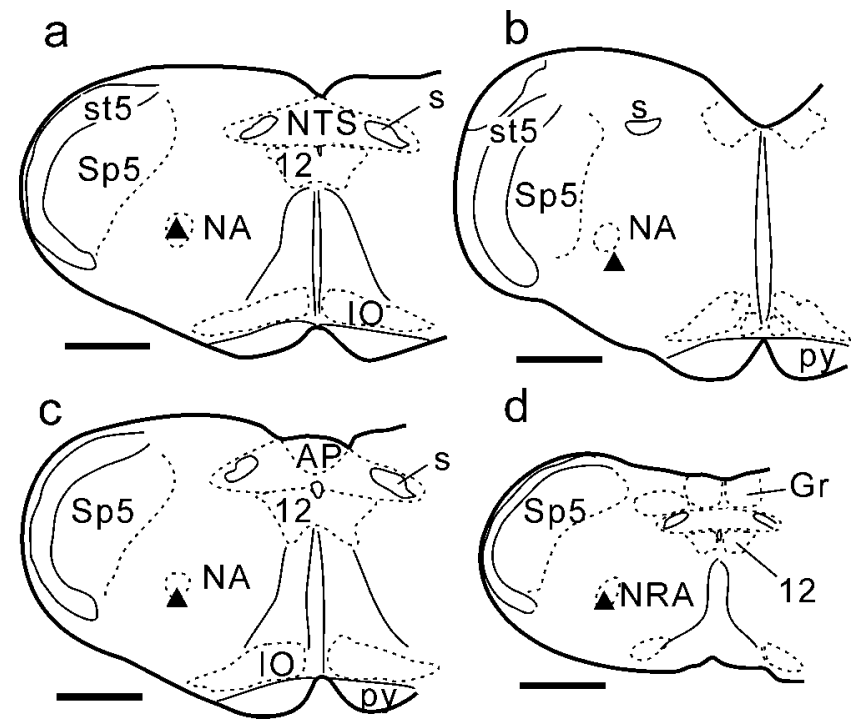

d

Figure 4. Location of E-DEC neurons. Filled triangles in $a-d$ represent E-DEC neurons shown in Figure $3 a 1$ (at the level of the obex), Figure $5 a 1$ (BOT level), Figure $6 a 1$ (rostral VRG), and Figure 661 (caudal VRG), respectively. AP, Area postrema; Gr, gracile nucleus; I0, inferior olivary nucleus; NRA, nucleus retroambiguus; NTS, nucleus tractus solitarii; py, pyramidal tract; 12, hypoglossal nucleus. Scale bars, $1 \mathrm{~mm}$.
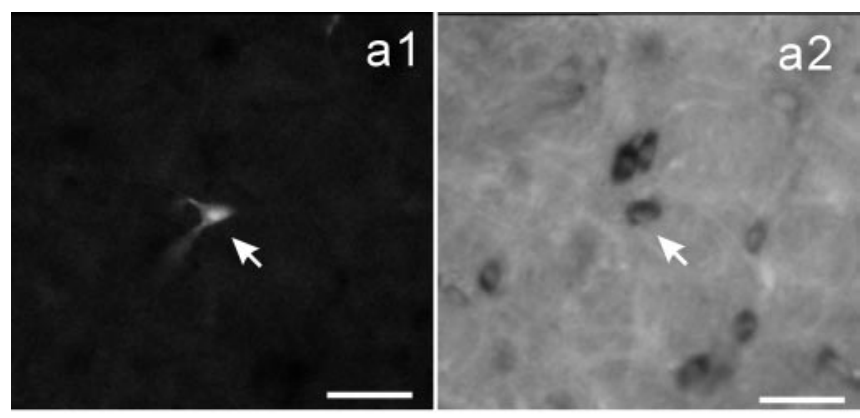

b
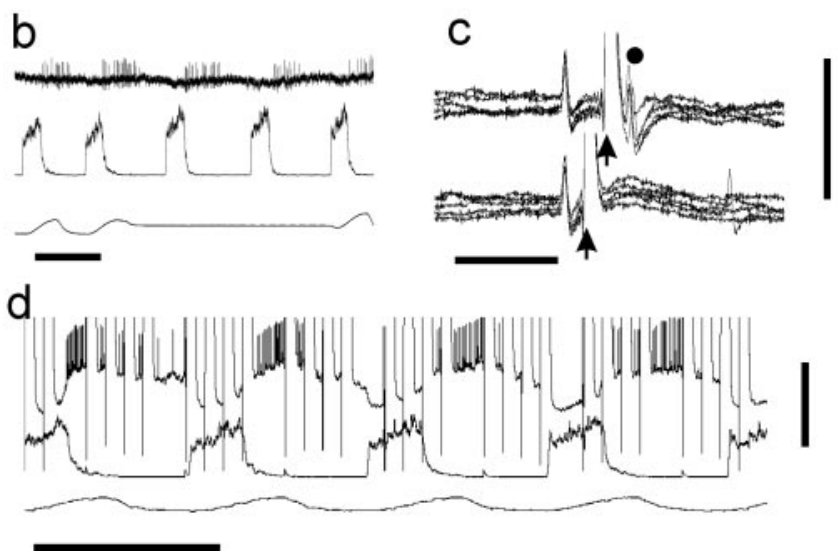

Figure 5. Example of a GLYT2-positive E-DEC neuron of the BOT. a1, Photomicrograph of a Neurobiotin-labeled E-DEC neuron (arrow, Cy3 fluorescence). a2, Photomicrograph of the same area of $a 1$ in bright-field shows that this neuron is GLYT2-positive (arrow). b, Extracellular recording just before penetration. $c$, Antidromic spikes were evoked from the ipsilateral caudal VRG. In the collision test a stimulus was applied $2 \mathrm{msec}$ (top traces) and $1 \mathrm{msec}$ (bottom traces) after spontaneous spikes ( 5 superimposed traces). $d$, Response during Neurobiotin injection. Scale bars, $50 \mu \mathrm{m}$ for photomicrographs. Calibration: $b, 1 \mathrm{sec} ; c, 5 \mathrm{msec}, 5 \mathrm{mV} ; d, 1 \mathrm{sec}, 20 \mathrm{mV}$.

recordings did not allow us to classify the labeled neurons by the membrane potential trajectories, at least four E-DEC neurons were confirmed to be early-onset type in GLYT2 experiments and were GLYT2-positive. 

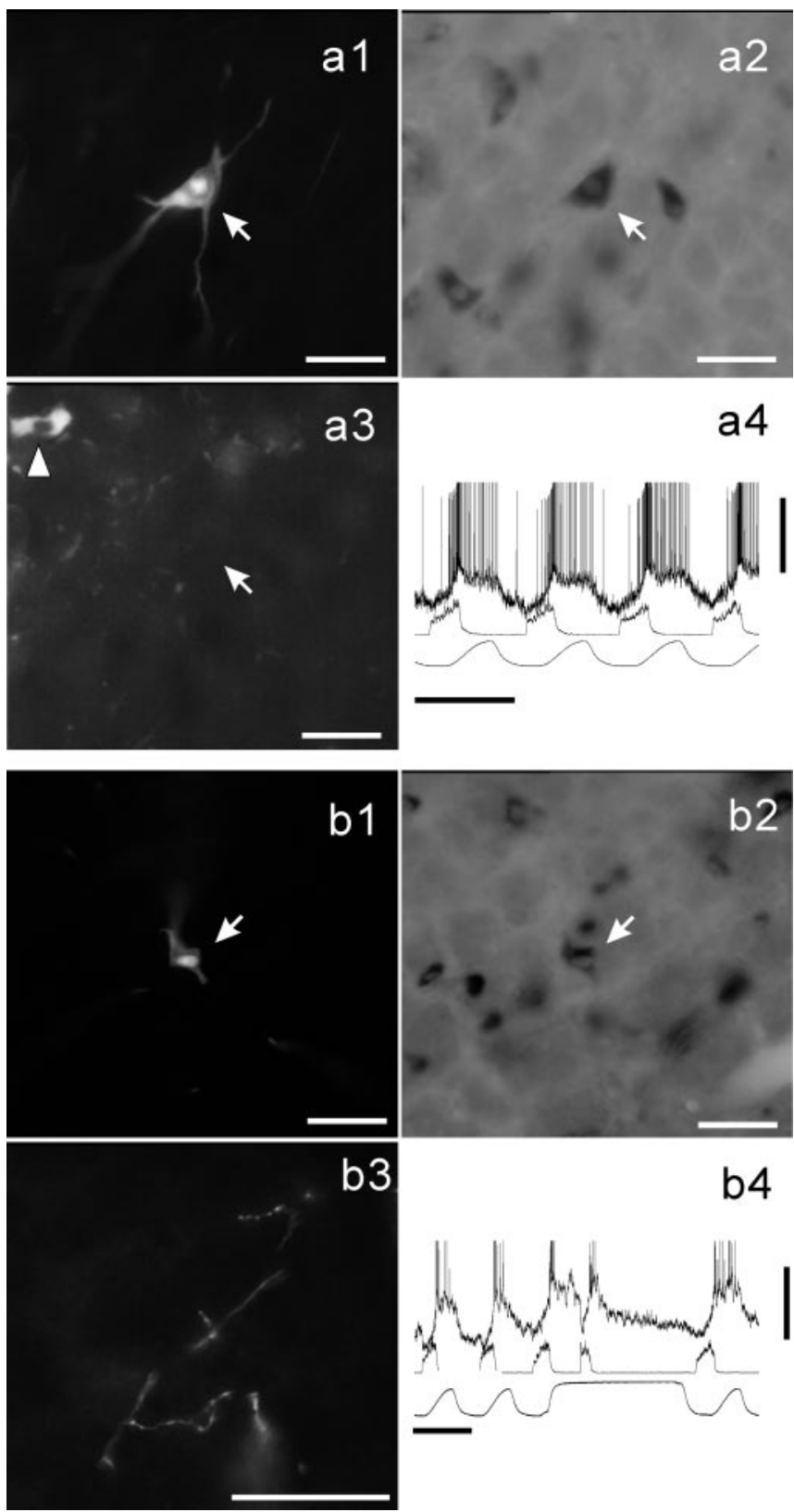

Figure 6. GLYT2-positive neurons of the VRG. Shown are Neurobiotin-labeled E-DEC neurons of the rostral VRG (a1, arrow) and the caudal VRG (b1, arrow). Both neurons are GLYT2positive ( $a 2$ and $b 2$, respectively). The neuron $a 1$ was located ventromedially to the cluster of ChAT-active motoneurons ( $a 3$, arrowhead). b3, Examples of the axonal branching and terminal boutons in the caudal VRG area arising from the neuron (b1, arrow). Membrane potential trajectories are shown in $a 4$ and $b 4$. Scale bars, $50 \mu \mathrm{m}$ for photomicrographs. Calibration: $a 4$, $b 4,1 \mathrm{sec}, 10 \mathrm{mV}$.

We could study the effect of lung inflation on the E-DEC activity either by stopping the ventilator and loading a positive pressure (e.g., Fig. 6b4) or by observing the change in neuronal activity evoked by the movements of the ventilator. In all of the E-DEC neurons that were examined $(n=15)$, their activity was increased during lung inflation.

Figure 8 maps all of the Neurobiotin-labeled E-DEC neurons $(n=38)$ and indicates that GLYT2-positive E-DEC neurons were distributed in the ventrolateral medulla from the BOT through the caudal VRG.
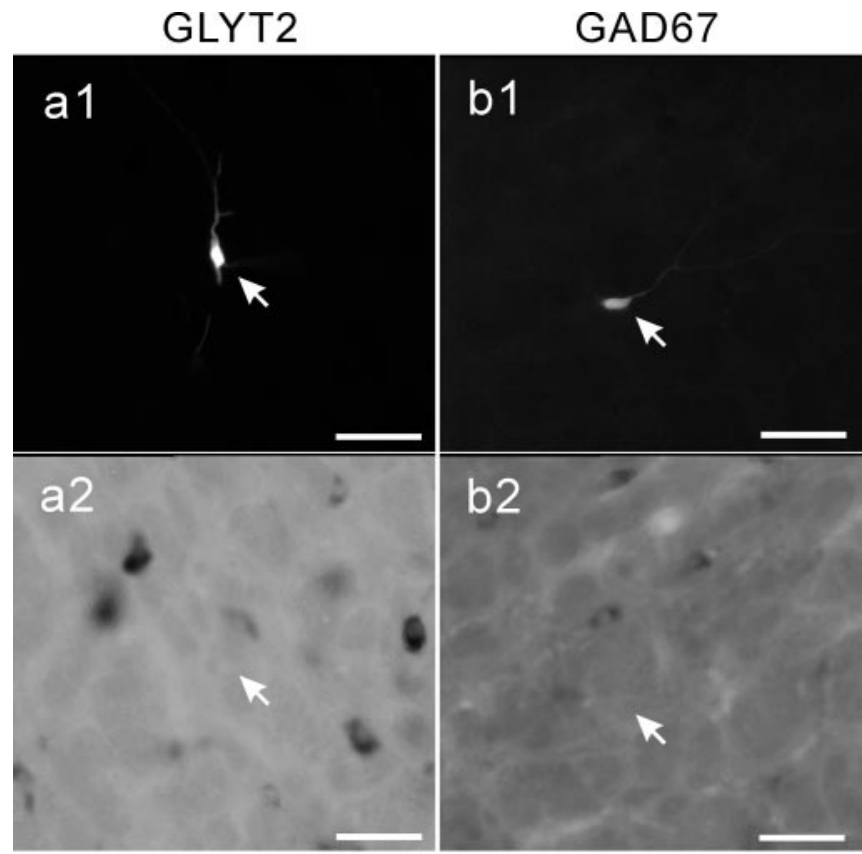

a3

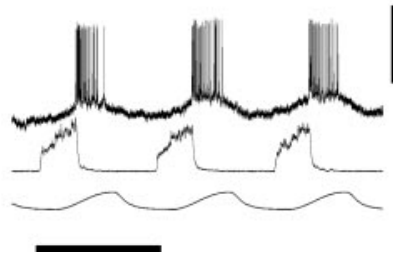

b3

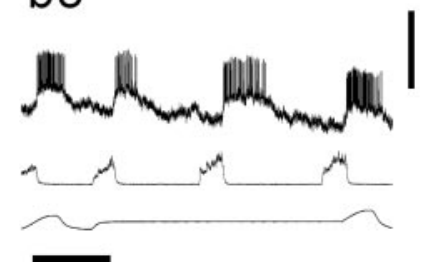

Figure 7. Examples of GLYT2-negative neuron and GAD67-negative neuron. A Neurobiotinlabeled E-DEC neuron examined for GLYT2 mRNA (a1, arrow) and a neuron examined for GAD67 mRNA (b1, arrow) are GLYT2-negative ( $a 2$ ) and GAD67-negative ( $b 2$ ), respectively. Membrane potential trajectories are shown in $a 3$ and $b 3$. Scale bars, $50 \mu \mathrm{m}$ for photomicrographs. Calibration: $a 3, b 3,1 \mathrm{sec}, 5 \mathrm{mV}$.

\section{Discussion}

The present study combined single-neuron labeling of physiologically identified E-DEC neurons with detection of mRNA markers for glycinergic and GABAergic neurons. The major finding of the present study is that (1) putative inhibitory E-DEC neurons use glycine rather than GABA as their neurotransmitter and (2) not only E-DEC neurons of the BOT but also many E-DEC neurons of the VRG are most probably inhibitory.

\section{E-DEC neurons of the BOT area}

The BOT first was defined functionally as the area of E-AUG neurons, which are the major inhibitory neurons (Merrill et al., 1983; Ezure, 1990; Jiang and Lipski, 1990; Tian et al., 1999). Schreihofer et al. (1999) has shown that this area includes dense GLYT2-positive neurons and has provided conclusive evidence that the E-AUG neurons are glycinergic, which we also have confirmed in the present study. As to E-DEC neurons of the BOT, which have been shown to be inhibitory in cats and rats (Lindsey et al., 1987; Ezure and Manabe, 1988; Shen et al., 2003), their neurotransmitter remains to be determined. The dense distribution of GLYT2-positive neurons in the BOT (Schreihofer et al., 1999; Tanaka et al., 2003) suggests the possibility that the E-DEC neurons are also glycinergic, because E-DEC neurons are distributed in the same area as E-AUG neurons (Ezure et al., 1988; Shen et al., 2003). 


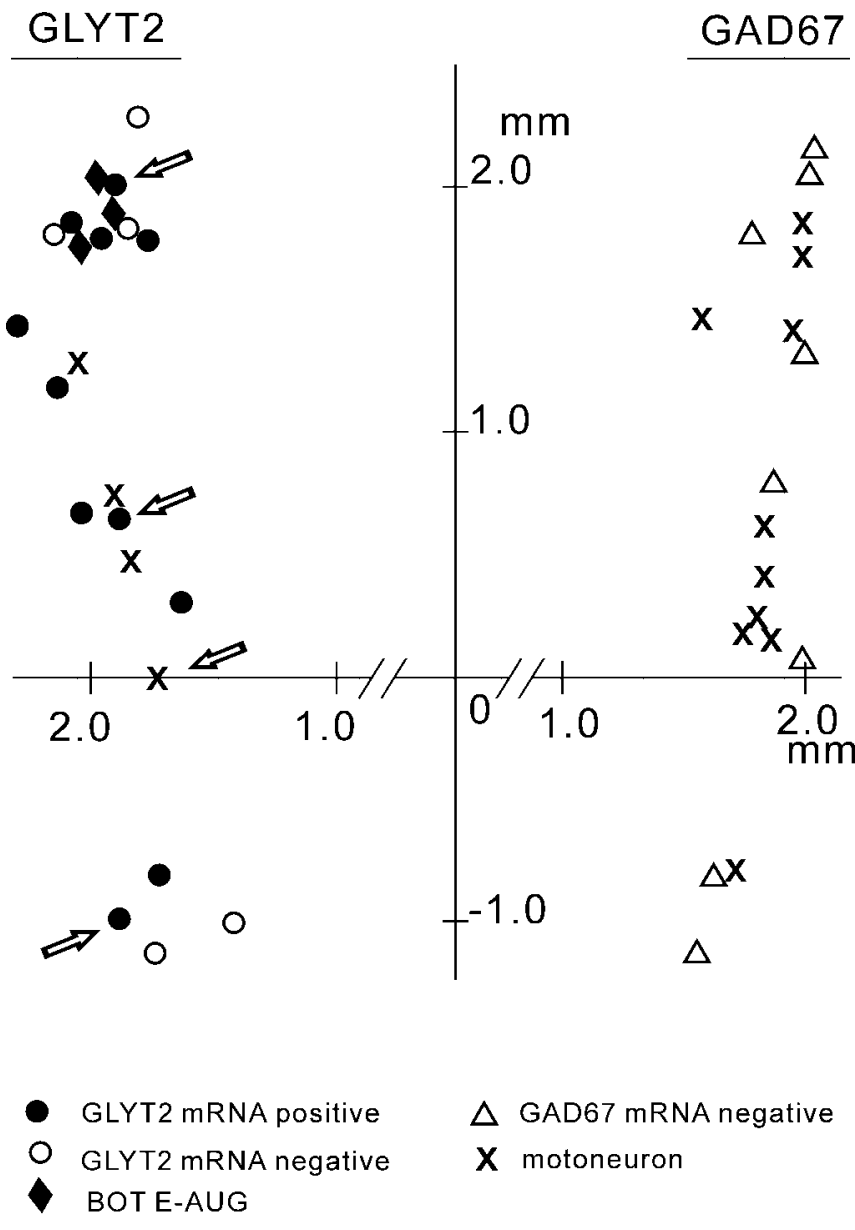

Figure 8. Distribution of the E-DEC neurons that were examined. Dorsal view of neuron location is based on the coordinates of manipulator readings. Neurons examined for GLYT2 mRNA are shown on the left and those for GAD67 mRNA on the right. Neurons with arrows are shown in Figure 4. The origin corresponds to the obex.

If we take into account the E-DEC neurons recorded in the rostral medulla at the level $1.5 \mathrm{~mm}$ or more rostral to the obex, which may correspond to BOT neurons (Fig. 8), four of the seven E-DEC neurons were GLYT2-positive. All three E-DEC neurons examined for GAD67 mRNA were GAD67-negative. These results may imply that, although E-DEC neurons are not necessarily inhibitory, "inhibitory E-DEC" neurons are glycinergic rather than GABAergic. These results contrast with E-AUG neurons. Schreihofer et al. (1999) showed that 10 of the 10 E-AUG neurons examined for GLYT2 mRNA were GLYT2-positive and that 10 of the 10 E-AUG neurons examined for GAD67 mRNA were GAD67-negative. It may be premature to conclude that E-AUG neurons of the BOT are all inhibitory, but E-DEC neurons of the BOT include both inhibitory and excitatory neurons. However, the observation that patterns of activity in E-DEC neurons differ between neurons and between preparations (Hayashi et al., 1996; Paton, 1996; Shen et al., 2003) suggests the possibility that E-DEC neurons of the BOT include subtypes. In fact, such a possibility has been revealed during nonrespiratory activities such as coughing, swallowing, or vomiting (Miller and Ezure, 1992; Oku et al., 1994). That is, E-DEC neurons that exhibit a decrementing firing pattern during respiration are classified into subtypes that exhibit different firing patterns during these nonrespiratory but closely related activities.

\section{E-DEC neurons of the VRG}

E-DEC neurons or postinspiratory neurons are distributed in the rostral and caudal VRG (Shiba et al., 1997; Okazaki et al., 2001; Saito et al., 2002; Shen and Duffin, 2002; Shen et al., 2003) as well as in the BOT. Many of them are cranial motoneurons (Zheng et al., 1991; Saito et al., 2002); still, many are interneurons with intramedullary projections to respiration-related areas (Anders et al., 1991; Zheng et al., 1991; Schwarzacher et al., 1992; Shiba et al., 1997; Saito et al., 2002) or to the spinal cord (Miller et al., 1987; Shen and Duffin, 2002). Many of them, in particular those in the caudal VRG, have both spinal and intramedullary projections (Saito et al., 2002). However, the functional role of these E-DEC neurons is unknown. A recent cross-correlation study by Shen et al. (2003) suggests that E-DEC neurons of the rostral VRG are inhibitory to respiratory neurons in the medulla and to phrenic motoneurons in the spinal cord. In addition, the observation that GLYT2-positive neurons cluster in the caudal VRG area suggests the possibility that E-DEC neurons of the caudal VRG are inhibitory (Tanaka et al., 2003). In the present study we assumed that if E-DEC neurons of the VRG are inhibitory they may express GLYT2 mRNA or GAD67 mRNA.

E-DEC neurons were labeled in the rostral and caudal VRG (Fig. 8). Seven of the nine VRG E-DEC neurons examined for GLYT2 mRNA were GLYT2-positive, and all five E-DEC neurons examined for GAD67 mRNA were GAD67-negative. This implies that (1) "inhibitory E-DEC" neurons exist not only in the BOT but also in the rostral and caudal VRG and (2) they use glycine rather than GABA as their neurotransmitter.

Okazaki et al. (2001) studied GABAergic neurons of the VRG by combining single-neuron labeling with immunohistochemical methods for detection of GAD and reported that all E-DEC (postinspiratory) neurons of the VRG that were examined ( $n=$ 3) were GAD-immunoreactive. The reason for the discrepancy between their results and the present results is unknown and remains to be studied. It should be noted that glycine and GABA often are colocalized in single neurons (Wenthold et al., 1987; Ottersen et al., 1988) and are co-released (Jonas et al., 1998); however, neither the present nor the previous (Okazaki et al., 2001) study has examined such a possibility. Furthermore, the present study has not taken into consideration the participation of GAD65, another GAD isoform (Erlander et al., 1991), either. With the reservation mentioned here, the present results show that many E-DEC neurons of the VRG express mRNA for GLYT2, which is a reliable marker for glycinergic neurons (Liu et al., 1993; Luque et al., 1995; Chan and Sawchenko, 1998; Schreihofer et al., 1999).

\section{Glycinergic versus GABAergic inhibition during the expiratory phase}

E-DEC and E-AUG neurons, the major inhibitory neurons, work during the early and the late expiratory phases, respectively. As to E-DEC neurons, the present results agree with previous electrophysiological and pharmacological studies (Champagnat et al., 1982; Schmid et al., 1996; Dutschmann and Paton, 2002a). These studies showed that after the administration of strychnine, a glycine receptor blocker, inspiratory activities were disinhibited in the early expiratory phase, suggesting that E-DEC (postinspiratory) neurons are glycinergic. As to E-AUG neurons, the same line of approach using bicuculline, a GABA receptor blocker, suggests that some E-AUG neurons are GABAergic (Champagnat et al., 1982; Haji et al., 1992; Schmid et al., 1996) and some are glycinergic as well (Schmid et al., 1996). Schreihofer et al. (1999) and the present study strongly suggest that E-AUG neurons are 
glycinergic, although these studies cannot rule out completely the possibility that some E-AUG neurons are GABAergic.

If both E-DEC and E-AUG neurons are glycinergic, blocking glycinergic transmission should modify seriously or even stop the respiratory rhythm. In fact, strychnine severely distorts the respiratory rhythm in rats (Hayashi and Lipski, 1992; Dutschmann and Paton, 2002b; St. John and Paton, 2002) and in mice (Büsselberg et al., 2001), often abolishing entirely the rhythm in rabbits (Schmid et al., 1991) and in cats (Pierrefiche et al., 1998). On the other hand, it is reported that the expiratory inhibition is maintained by GABAergic input with relatively little contribution from glycinergic transmission in dogs (Krolo et al., 2000). Furthermore, the data that strychnine severely distorts but does not necessarily stop the rhythm (Büsselberg et al., 2001; Dutschmann and Paton, 2002b) may not support the notion that the glycinergic process only is important. Thus the question as to how the glycinergic and GABAergic processes are organized remains unanswered. Nevertheless, the glycinergic process via E-DEC and E-AUG neurons is certainly an essential component of the expiratory inhibition.

\section{Conclusion}

No doubt, our knowledge about E-DEC neurons is limited. We do not know whether "excitatory E-DEC" interneurons exist or not. We do not know whether E-DEC neurons of the BOT and the VRG belong to the same or different population, either. In fact, the firing patterns of E-DEC neurons are various (Hayashi et al., 1996; Dutschmann and Paton, 2002b; Shen et al., 2003). When their firing starts early, overlapping with the inspiratory phase, the discrimination between them and late-onset inspiratory neurons (Hayashi et al., 1996; Okazaki et al., 2001) is vague. Furthermore, whether E-DEC neurons (Ezure and Manabe, 1988; Ezure, 1990) and postinspiratory neurons (Richter, 1982; Richter et al., 1986; Schwarzacher et al., 1991) belong to the same or different population is not clear (Rybak et al., 1997). On the other hand, it is a consistent observation that these neurons receive facilitatory effect from lung inflation, suggesting excitatory effects from the slowly adapting lung stretch receptors (Feldman and Cohen, 1978; Remmers et al., 1986; Manabe and Ezure, 1988; Hayashi et al., 1996; Mellen and Feldman, 2001). During normal respiration this facilitatory effect is clearly suitable for E-DEC neurons to start firing at approximately the time of the inspiration-expiration transition, suggesting their critical role in this transition.

Although the characterization of E-DEC neurons is not sufficient and the contribution of GABA is not denied completely, the present study strongly suggests that "inhibitory E-DEC" neurons use glycine as a transmitter. Because the E-AUG neurons of the BOT are also glycinergic, the present results imply that the phasic inhibition of the respiratory network during the expiratory phase is produced mostly, if not entirely, by glycinergic neurons.

\section{References}

Anders K, Schwarzacher SW, Richter DW (1991) Morphology of postinspiratory neurons in the cat. Pflügers Arch 418[Suppl 1]:R16.

Bianchi AL, Barillot JC (1982) Respiratory neurons in the region of the retrofacial nucleus: pontile, medullary, spinal and vagal projections. Neurosci Lett 31:277-282.

Bieger D, Hopkins DA (1987) Viscerotopic representation of the upper alimentary tract in the medulla oblongata in the rat: the nucleus ambiguus. J Comp Neurol 262:546-562.

Bryant T, Yoshida S, De Castro D, Lipski J (1993) Expiratory neurons of the Bötzinger complex in the rat: a morphological study following intracellular labeling with biocytin. J Comp Neurol 335:267-282.
Büsselberg D, Bischoff AM, Paton JFR, Richter DW (2001) Reorganization of respiratory network activity after loss of glycinergic inhibition. Pflügers Arch 441:444-449.

Champagnat J, Denavit-Saubié M, Moyanova S, Rondouin G (1982) Involvement of amino acids in periodic inhibitions of bulbar respiratory neurones. Brain Res 237:351-365.

Chan RKW, Sawchenko PE (1998) Organization and transmitter specificity of medullary neurons activated by sustained hypertension: implications for understanding baroreceptor reflex circuitry. J Neurosci 18:371-387.

Cox KH, DeLeon DV, Angerer LM, Angerer RC (1984) Detection of mRNAs in sea urchin embryos by in situ hybridization using asymmetric RNA probes. Dev Biol 101:485-502.

Duffin J, Ezure K, Lipski J (1995) Breathing rhythm generation: focus on the rostral ventrolateral medulla. News Physiol Sci 10:133-140.

Dutschmann M, Paton JFR (2002a) Trigeminal reflex regulation of the glottis depends on central glycinergic inhibition in the rat. Am J Physiol Regul Integr Comp Physiol 282:R999-R1005.

Dutschmann M, Paton JFR (2002b) Glycinergic inhibition is essential for co-ordinating cranial and spinal respiratory motor outputs in the neonatal rat. J Physiol (Lond) 543:643-653.

Erlander MG, Tillakaratne NJK, Feldblum S, Patel N, Tobin AJ (1991) Two genes encode distinct glutamate decarboxylases. Neuron 7:91-100.

Esclapez M, Tillakaratne NJK, Kaufman DL, Tobin AJ, Houser CR (1994) Comparative localization of two forms of glutamic acid decarboxylase and their mRNAs in rat brain supports the concept of functional differences between the forms. J Neurosci 14:1834-1855.

Ezure K (1990) Synaptic connections between medullary respiratory neurons and considerations on the genesis of respiratory rhythm. Prog Neurobiol 35:429-450.

Ezure K, Manabe M (1988) Decrementing expiratory neurons of the Bötzinger complex. II. Direct inhibitory synaptic linkage with ventral respiratory group. Exp Brain Res 72:159-166.

Ezure K, Manabe M, Yamada H (1988) Distribution of medullary respiratory neurons in the rat. Brain Res 455:262-270.

Feldman JL, Cohen MI (1978) Relation between expiratory duration and rostral medullary expiratory neuronal discharge. Brain Res 141:172-178.

Grélot L, Barillot JC, Bianchi AL (1989) Pharyngeal motoneurons: respiratory-related activity and responses to laryngeal afferents in the decerebrate cat. Exp Brain Res 78:336-344.

Haji A, Takeda R, Remmers JE (1992) Evidence that glycine and GABA mediate postsynaptic inhibition of bulbar respiratory neurons in the cat. J Appl Physiol 73:2333-2342.

Haji A, Takeda R, Okazaki M (2000) Neuropharmacology of control of respiratory rhythm and pattern in mature mammals. Pharmacol Ther 86:277-304.

Hayashi F, Lipski J (1992) The role of inhibitory amino acids in control of respiratory motor output in an arterially perfused rat. Respir Physiol $89: 47-63$

Hayashi F, Coles SK, McCrimmon DR (1996) Respiratory neurons mediating the Breuer-Hering reflex prolongation of expiration in rat. J Neurosci 16:6526-6536.

Ichikawa T, Ohsako S, Deguchi T (1991) Production of an antiserum using a fusion protein produced by a cDNS for rat choline acetyltransferase. Neurosci Lett 131:213-216.

Ichikawa T, Ajiki K, Matsuura J, Misawa H (1997) Localization of two cholinergic markers, choline acetyltransferase and vesicular acetylcholine transporter in the central nervous system of the rat: in situ hybridization histochemistry and immunohistochemistry. J Chem Neuroanat 13:23-39.

Iizuka M (1999) Intercostal expiratory activity in an in vitro brainstemspinal cord-rib preparation from the neonatal rat. J Physiol (Lond) 520:293-302.

Jiang C, Lipski J (1990) Extensive monosynaptic inhibition of ventral respiratory group neurons by augmenting neurons in Bötzinger complex in the cat. Exp Brain Res 81:639-648.

Jonas P, Bischofberger J, Sandkühler J (1998) Corelease of two fast neurotransmitters at a central synapse. Science 281:419-424.

Kondo M, Sumino R, Okado H (1997) Combinations of AMPA receptor subunit expression in individual cortical neurons correlate with expression of specific calcium-binding proteins. J Neurosci 17:1570-1580.

Krolo M, Stuth EA, Tonkovic-Capin M, Hopp FA, McCrimmon DR, Zuperku EJ (2000) Relative magnitude of tonic and phasic synaptic excita- 
tion of medullary inspiratory neurons in dogs. Am J Physiol Regul Integr Comp Physiol 279:R639-R649.

Lindsey BG, Segers LS, Shannon R (1987) Functional associations among simultaneously monitored lateral medullary respiratory neurons in the cat. II. Evidence for inhibitory actions of expiratory neurons. J Neurophysiol 57:1101-1117.

Liu Q-R, Lopez-Coreuera B, Mandiyan S, Nelson H, Nelson N (1993) Cloning and expression of a spinal cord- and brain-specific glycine transporter with novel structural features. J Biol Chem 268:22802-22808.

Luque JM, Nelson N, Richards JG (1995) Cellular expression of glycine transporter 2 messenger RNA exclusively in rat hindbrain and spinal cord. Neuroscience 64:525-535.

Manabe M, Ezure K (1988) Decrementing expiratory neurons of the Bötzinger complex. I. Response to lung inflation and axonal projection. Exp Brain Res 72:150-158.

Mellen NM, Feldman JL (2001) Phasic vagal sensory feedback transforms respiratory neuron activity in vitro. J Neurosci 21:7363-7371.

Merrill EG, Lipski J, Kubin L, Fedorco L (1983) Origin of the expiratory inhibition of nucleus tractus solitarius inspiratory neurons. Brain Res 263:43-50.

Miller AD, Ezure K (1992) Behavior of inhibitory and excitatory propriobulbar respiratory neurons during fictive vomiting. Brain Res 578:168-176.

Miller AD, Tan LK, Suzuki I (1987) Control of abdominal and expiratory intercostal muscle activity during vomiting: role of ventral respiratory group expiratory neurons. J Neurophysiol 57:1854-1866.

Okazaki M, Takeda R, Haji A, Yamazaki H (2001) Glutamic acid decarboxylase-immunoreactivity of bulbar respiratory neurons identified by intracellular recording and labeling in rats. Brain Res 914:34-47.

Oku Y, Tanaka I, Ezure K (1994) Activity of bulbar respiratory neurons during fictive coughing and swallowing in the decerebrate cat. J Physiol (Lond) 480:309-324.

Otake K, Nakamura Y, Tanaka I, Ezure K (2001) Morphology of pulmonary rapidly adapting receptor relay neurons in the rat. J Comp Neurol 430:458-470.

Ottersen OP, Storm-Mathisen J, Somogyi P (1988) Colocalization of glycine-like and GABA-like immunoreactivities in Golgi cell terminals in the rat cerebellum: a postembedding light and electron microscopic study. Brain Res 450:342-353.

Paton JFR (1996) The ventral medullary respiratory network of the mature mouse studied in a working heart-brainstem preparation. J Physiol (Lond) 494:819-831.

Paton JFR, Richter DW (1995) Role of fast inhibitory synaptic mechanisms in respiratory rhythm generation in the maturing mouse. J Physiol (Lond) 484:505-521.

Paxinos G, Watson C (1998) The rat brain in stereotaxic coordinates, 4th Ed. San Diego: Academic.

Pierrefiche O, Schwarzacher SW, Bischoff AM, Richter DW (1998) Blockage of synaptic inhibition within the pre-Bötzinger complex in the cat supresses respiratory rhythm generation in vivo. J Physiol (Lond) 509:245-254.

Pilowsky PM, Makeham J (2001) Juxtacellular labeling of identified neurons: kiss the cells and make them dye. J Comp Neurol 433:1-3.

Pinault D (1996) A novel single-cell staining procedure performed in vivo under electrophysiological control: morpho-functional features of juxtacellularly labeled thalamic cells and other central neurons with biocytin or Neurobiotin. J Neurosci Methods 65:113-136.

Remmers JE, Richter DW, Ballantyne D, Bainton CR, Klein JP (1986) Reflex prolongation of stage I of expiration. Pflügers Arch 407:190-198.

Richter DW (1982) Generation and maintenance of the respiratory rhythm. J Exp Biol 100:93-107.

Richter DW, Ballantyne D, Remmers JE (1986) How is the respiratory rhythm generated? A model. News Physiol Sci 1:109-112.

Rybak IA, Paton JFR, Schwaber JS (1997) Modeling neural mechanisms for genesis of respiratory rhythm and pattern. II. Network models of the central respiratory pattern generator. J Neurophysiol 77:2007-2026.

Saito Y, Ezure K, Tanaka I (2002) Morphology of the decrementing expiratory neurons in the brainstem of the rat. Neurosci Res 44:141-153.

Schmid K, Bohmer G, Gebauer K (1991) Glycine receptor-mediated synaptic inhibition in the brainstem respiratory system. Respir Physiol 84:351-361.

Schmid K, Foutz AS, Denavit-Saubie M (1996) Inhibitions mediated by glycine and $\mathrm{GABA}_{\mathrm{A}}$ receptors shape the discharge pattern of bulbar respiratory neurons. Brain Res 710:150-160.

Schreihofer AM, Stornetta RL, Guyenet PG (1999) Evidence for glycinergic respiratory neurons: Bötzinger neurons express mRNA for glycinergic transporter 2. J Comp Neurol 407:583-597.

Schwarzacher SW, Wilhelm Z, Anders K, Richter DW (1991) The medullary respiratory network in the rat. J Physiol (Lond) 435:631-644.

Schwarzacher SW, Maschket M, Rudolph T, Richter DW (1992) GABAand serotonin-ergic innervation of medullary postinspiratory neurons in the cat. Soc Neurosci Abstr 18:313.

Shen L, Duffin J (2002) Caudal expiratory neurones in the rat. Pflügers Arch 444:405-410.

Shen L, Li YM, Duffin J (2003) Inhibitory connections among rostral medullary expiratory neurones detected with cross-correlation in the decerebrate rat. Pflügers Arch 446:365-372.

Shiba K, Umezaki T, Zheng Y, Miller AD (1997) The nucleus retroambigualis controls laryngeal muscle activity during vocalization in the cat. Exp Brain Res 115:513-519.

St. John WM, Paton JFR (2002) Neurogenesis of gasping does not require inhibitory transmission using $\mathrm{GABA}_{\mathrm{A}}$ or glycine receptors. Respir Physiol Neurobiol 132:265-277.

Stornetta RL, Guyenet PG (1999) Distribution of glutamic acid decarboxylase in rat medulla projecting to thoracic spinal cord in relation to monoaminergic brainstem neurons. J Comp Neurol 407:367-380.

Tanaka I, Ezure K, Kondo M (2003) Distribution of glycine transporter 2 mRNA-containing neurons in relation to glutamic acid decarboxylase mRNA-containing neurons in rat medulla. Neurosci Res 47:139-151.

Tian G-F, Peever JH, Duffin J (1999) Bötzinger-complex, bulbospinal expiratory neurones monosynaptically inhibit ventral-group respiratory neurones in the decerebrate rat. Exp Brain Res 124:173-180.

Wenthold RJ, Huie D, Altschuler RA, Reeks KA (1987) Glycine immunoreactivity localized in the cochlear nucleus and superior olivary complex. Neuroscience 22:897-912.

Zheng Y, Barillot JC, Bianchi AL (1991) Are the post-inspiratory neurons in the decerebrate rat cranial motoneurons or interneurons? Brain Res 551: $256-266$. 